\title{
Detection of antigens on mouse giant trophoblast cells after incubation with an inhibitor of glycoprotein synthesis
}

\author{
Jan Carter
}

\author{
Biochemistry Department, Trinity College, Dublin 2, Ireland
}

\begin{abstract}
Summary. The effect of 6-diazo-6-oxo-L-norleucine (DON), a glutamine analogue, on the development and expression of histocompatibility antigens on primary and secondary giant trophoblast cells has been examined in CBA and C57BL/10ScSn $(\mathrm{ScSn})$ mice. Blastocyst development was normal in concentrations of $<0.5 \mu \mathrm{g}$ $\mathrm{DON} / \mathrm{ml}$, and although there was no change in the expression of antigenic determinants on CBA primary giant trophoblast cells, $\mathrm{ScSn}$ cells showed an increase. These strain-specific antigens which were not normally expressed on secondary giant trophoblast cells were detected on CBA and $\mathrm{ScSn}$ ectoplacental cone outgrowths after incubation with DON. The effect of DON could be reversed when tissue was incubated with DON + glutamine. Expression of Thy-1.2 antigen and Ig molecules on lymphocytes was unaffected by DON. It is suggested that the giant trophoblast cells of the ectoplacental cone produce a cell surface component which masks antigenic determinants and that there are differences in the amount of the masking agent produced by the primary giant trophoblast cells of the two strains of mouse.
\end{abstract}

\section{Introduction}

Two kinds of giant trophoblast cells can be distinguished in mice. On Day 4 of pregnancy, the mouse blastocyst hatches from the zona pellucida and attaches to the uterine epithelium (Gardner, 1975). At this stage the abembryonic or mural trophoblast gives rise to the highly invasive primary giant trophoblast cells (Kirby \& Cowell, 1968) and the polar trophoblast overlying the inner cell mass forms the ectoplacental cone. While polar trophoblast remains diploid and undifferentiated (Hernandez-Verdun, 1974), the highly invasive secondary giant trophoblast cells which arise from its superficial regions erode into the maternal blood spaces and so become the only embryonic element in direct and continuous contact with the maternal tissues.

Primary giant trophoblast cells express maternal and paternal histocompatibility antigens detected by antibodies raised against spleen cells (Carter, 1976; Sellens, 1977). Secondary giant cells of the ectoplacental cone do not express antigens in vitro (Carter, 1978) until they have been in culture for approximately 4 days (Billington, Jenkinson, Searle \& Sellens, 1977; Carter, 1978). H-2 antigens have been found on trophoblast cells in mice 14-18 days pregnant (Chatterjee-Hasrouni \& Lala, 1979), which suggests that mechanisms other than an absence of transplantation antigens operate to protect the feto-placental unit. For example, antigens may be absent from the layer of trophoblast in direct contact with the maternal circulation. Alternatively membrane-associated components may mask surface antigens.

Whole placenta contains a mass of amorphous material termed "fibrinoid" (Grösser, 1925). 
This layer is a negatively charged glycoprotein deposit with a high content of sialic and hyaluronic acid residues and has been suggested as a masking agent for surface antigens (Bulmer \& Dickinson, 1961; Kirby, Billington, Bradbury \& Goldstein, 1964; Bradbury, Billington \& Kirby, 1965; Currie \& Bagshawe, 1967). There have been conflicting reports of the antigenicity of neuraminidase-treated ectoplacental cones. Currie, van Doorninck \& Bagshawe (1968) and Taylor, Hancock \& Gowland (1979) were able to unmask histocompatibility antigens on trophoblast but Simmons, Lipschultz, Rios \& Ray (1971) and Searle, Jenkinson \& Johnson (1975) were unable to confirm these results. However, there is a neuraminidase-sensitive glycopeptide containing glucosamine-derived metabolic products, particularly sialic acid, on the surface of human trophoblast cells that is not present on fetal cells from the same embryo (Whyte \& Loke, 1978). Sialic and hyaluronic acid residues are involved in glycoprotein and glycosaminoglycan structure. The synthesis of glycosaminoglycan and glycoproteins can be inhibited by the glutamine analogue 6-diazo-5-oxo-L-norleucine (DON) which blocks the utilization of glutamine in transamidination reactions (Ghosh, Blumenthal, Davidson \& Roseman, 1960; Buchanan, 1973). DON has been shown to inhibit the formation of basement membrane and cell surface structures in a number of experimental systems: cartilage formation of mouse limb buds (Greene \& Kochlar, 1975); odontoblast differentiation (Hurmerinta, Thesleff \& Saxén, 1979); and kidney tubule induction (Ekblom, Lash, Lehtonen, Nordling \& Saxén, 1979). In addition, DON inhibits the synthesis of hyaluronic acid by $80 \%$ and other sulphated mucopolysaccharides by approximately $65 \%$ in palatal cell adhesion (Greene \& Pratt, 1977). The present study reports the effect of DON on the cell surface antigen expression of primary and secondary giant trophoblast cells.

\section{Materials and Methods}

\section{Animals and antisera}

The mice used were the CBA and $\mathrm{C} 57 \mathrm{BL} / 10 \mathrm{ScSn}(\mathrm{ScSn})$ inbred strains maintained in the Wellcome Animal Laboratories, Trinity College. The day of finding a vaginal plug was designated Day 1 of pregnancy. Antisera were made by cross-immunization between the two mouse strains of half a spleen injected intraperitoneally each week for 7-10 weeks. Specificity of antisera was tested against appropriate target lymphocytes in a dye-exclusion complementdependent cytotoxicity test.

\section{Primary and secondary giant trophoblast cells}

Details of trophoblast culture have been given elsewhere (Carter, 1978). Briefly, blastocysts were flushed from the uteri of Day-4 pregnant mice with phosphate-buffered saline (PBS), pH 7.3. They were cultured in Snow C medium (Ansell \& Snow, 1975) $+10 \%$ fetal calf serum (FCS) (Gibco Bio-Cult, Paisley, Scotland) on acid-washed sterile coverslips under oil and maintained at $37^{\circ} \mathrm{C}$ in an atmosphere of air with $5 \% \mathrm{CO}_{2}$ controlled by a $\mathrm{CO}_{2}$ monitor (Gow-Mac Instruments, Shannon, Ireland). When the blastocysts had hatched, attached and the primary giant cells begun to outgrow, the outgrowth was designated 'ao'. Approximately 1 day later outgrowth was complete and the culture was designated ' $o$ '.

Secondary giant cells from ectoplacental cone trophoblast were obtained by dissection of embryos on Day 8 of pregnancy. The cells were cultured in Trowell's T-8 Medium (Gibco Bio-Cult) supplemented with $10 \%$ FCS. The medium was changed after $48 \mathrm{~h}$. Other culture conditions were identical to those described for blastocyst culture. During the first $24 \mathrm{~h}$, the ectoplacental cone tissue attached and a few layers of secondary giant cells outgrew. This was designated 'ao'. The radius of the outgrowths continued to increase and later stages were designated ' 0 '. 
DON, glutamine and glucosamine

DON (a gift from the National Institutes of Health, Bethesda, Maryland, U.S.A.) was stored in powder form at $-20^{\circ} \mathrm{C}$. Solutions of DON, L-glutamine and D-glucosamine (Sigma Chemical Co., Poole, U.K.) were made up fresh in Trowells T-8 Medium + 10\% FCS for each experiment.

\section{Mixed haemadsorption test and preparation of indicator cells}

The test used was that of Fagraeus, Espmark \& Jonsson (1965) and has been described in detail, with all specificity controls, elsewhere (Carter, 1978). Briefly, cultures of trophoblast cells were incubated for $1 \mathrm{~h}$ at $37^{\circ} \mathrm{C}$ with a $1: 160$ dilution of ScSn anti-CBA serum or a $1: 40$ dilution of CBA anti-ScSn serum. After 3 rinses with PBS the cultures were layered with sensitized sheep red blood cells (RBC) for $1 \mathrm{~h}$ at room temperature. Unattached erythrocytes were washed off and the amount of attachment was estimated by examination with phase-contrast microscopy. Blastocyst outgrowths were scored according to the percentage of target cells of the whole outgrowth to which the sensitized sheep RBCs were attached. Secondary giant cells were scored according to the percentage of target cells on the outermost layer of the outgrowth to which the indicator cells were attached. The score was expressed on the following scale: 4.0 (100\% attachment), 3.5 (90\%), 3.0 (50-80\%), 2.0 (25-50), 1.0 (10-25\%), 0.5 (1-10\%) (Carter, 1976).

Permanent mounts of outgrowths were made by fixation for $1 \mathrm{~h}$ in $10 \%$ buffered formalin, followed by staining with haematoxylin and eosin and mounting with neutral glycerine jelly.

\section{Lymphocyte culture and indirect immunofluorescence}

Lymph nodes and thymus glands of CBA mice were dissociated through a fine wire mesh and the cells were washed twice with Hanks' balanced salt solution. They were cultured at a concentration of $5 \times 10^{6}$ cells per well with or without DON in medium RPMI (Gibco Bio-Cult) plus $10 \%$ FCS in microtitre plates. After $24 \mathrm{~h}$ the cells were washed twice and cell surface immunoglubulin was identified by means of rabbit anti-mouse IgG (Fab $)_{2}$ fraction (Cappel Laboratories, Cochranville, U.S.A.) and rhodamine-labelled goat anti-rabbit immunoglobulin (Nordic Immunological Laboratories, Maidenhead, U.K.) (Hudson \& Hay, 1976). The T-lymphocyte membrane antigen, Thy-1.2, was identified by means of monoclonal F7D5 Thy-1.2 antibody (Olac 1976, Bicester, U.K.) and fluorescene-labelled rabbit anti-mouse IgM (Nordic Immunological Laboratories, Maidenhead, U.K.) (Lake, Clark, Khorshidi \& Sunshine, 1979). All incubations were for $30 \mathrm{~min}$ at $4^{\circ} \mathrm{C}$ with $15 \mu \mathrm{l}$ of an appropriate dilution of antiserum. Samples were washed twice after the first incubation and three times after the second. Cells were examined under a coverslip for surface immunofluorescence using a Zeiss Jena microscope equipped with phase-contrast incidence-fluorescence optics and an Osram HBO 200 mercury arc lamp. Two hundred cells were examined for each treatment.

\section{Results}

Effect of DON on blastocyst development and antigenic expression

Embryos $(>10)$ cultured in medium containing $0.5,1,10$ or $20 \mu \mathrm{g} \mathrm{DON} / \mathrm{ml}$ were dead after $24 \mathrm{~h}$. Blastocysts in culture medium containing 0.01 or $0.1 \mu \mathrm{g} \mathrm{DON} / \mathrm{ml}$ showed the same rate of development as control blastocysts. Expanded blastocysts flushed from the uteri on Day 4 of pregnancy were hatching or had hatched after $24 \mathrm{~h}$ in culture. After 48-72 h they were either attached and outgrowing ('ao') or were outgrown ('o'). If non-expanded blastocysts or morulae were put into culture with DON then development was delayed for 24-48 h. 
When morulae were cultured in 0.5 or $1.0 \mu \mathrm{g} \mathrm{DON} / \mathrm{ml}$, they showed cavitation and expansion but did not hatch and eventually died. Blastocysts and expanded blastocysts also failed to hatch and eventually died.

Table 1 shows the effects of different concentrations of DON on the antigenic expression of blastocyst outgrowths.

Table 1. The effect of DON on antigen expression of blastocyst 'ao' and 'o' outgrowths

\begin{tabular}{cccc}
\hline $\begin{array}{c}\text { DON } \\
(\mu \mathrm{g} / \mathrm{ml})\end{array}$ & $\begin{array}{c}\text { Type of } \\
\text { outgrowth }\end{array}$ & $\begin{array}{c}\text { CBA cells } \\
\text { incubated with anti-CBA serum }\end{array}$ & $\begin{array}{c}\text { ScSn cells } \\
\text { incubated with anti-ScSn serum }\end{array}$ \\
\hline 0 (control) & 'ao' & $4.0(5)$ & $2.5 \pm 0.5(4)$ \\
& 'o' & $3.91 \pm 0.08(12)$ & $2.08 \pm 0.37(6)$ \\
0.01 & 'o' & $4.0(10)$ & $\mathrm{NE}$ \\
0.1 & 'ao' & $4.0(11)$ & $\mathrm{NE}$ \\
& 'o' & $4.0(6)$ & $4.0(8)$ \\
0.5 & & Dead (4) & Dead (4) \\
1.0 & & Dead (6) & NE \\
10.0 & & Dead (20) & Dead (13) \\
20.0 & & Dead (20) & Dead (13) \\
\hline
\end{tabular}

Results expressed as mean score (see text) \pm s.e.m. The no. of outgrowths examined is given in parentheses. $\mathrm{NE}=$ not examined.

Effect of DON, glucosamine and glutamine on the development and antigen expression of ectoplacental cone outgrowths

Ectoplacental cones cultured in $0.01,0.1,1,10$ or $20 \mu \mathrm{g} \mathrm{DON} / \mathrm{ml}$ showed normal development for the first $24-48 \mathrm{~h}$ in culture. The tissue attached to the coverslip and giant cells outgrew (Carter, 1978). After 2-4 days the cells of outgrowths in 1, 10 or $20 \mu \mathrm{g} \mathrm{DON} / \mathrm{ml}$ lost their ability to adhere both to each other and to the coverslip, and after 4 days in culture were dead. At doses of 0.01 and $0.1 \mu \mathrm{g} \mathrm{DON} / \mathrm{ml}$, development was normal for the first 2 days but then varied numbers of cells in the outgrowth became rounded and were in suspension culture (Pl. 1, Fig. 1). This lack of adhesion was overcome after incubation with DON $(0.1,1$ and 20 $\mu \mathrm{g} / \mathrm{ml})$ plus glutamine $(10 \mathrm{~mm})$ for 2-4 days. However, secondary giant cells cultured in glucosamine $(10 \mathrm{mM})+$ DON attached to the coverslip during the first $24 \mathrm{~h}$ but did not outgrow and were usually dead after $24 \mathrm{~h}$ in culture. Glucosamine at $5 \mathrm{~mm}$ was not toxic but did not overcome the inhibitory effect of DON.

The effect of DON on the antigenic expression of 'ao' outgrowths of ectoplacental cones is shown in Table 2. The CBA $\times$ CBA 'ao' outgrowths after incubation with anti-CBA serum in the MHA gave the expected score of zero and 'o' outgrowths a score of 4.0 (Carter, 1978). Cultures incubated with all DON concentrations to the 'ao' stage gave scores of 4.0 (Pl. 1, Fig. 2) and sensitized sheep RBCs were attached to all the cells of the outgrowth. Cultures until the 'o' stage in $0.1 \mu \mathrm{g} D O N / \mathrm{ml}$ were also totally covered by sensitized sheep RBCs as compared to control ' $o$ ' outgrowths of which only the outer layers were labelled. CBA $\times$ CBA 'ao' outgrowths grown in 1.0 or $10 \mu \mathrm{g} \mathrm{DON} / \mathrm{ml}$ and incubated with control anti-ScSn serum gave negative scores.

Similar results were obtained for ScSn $\times$ ScSn 'ao' and 'o' outgrowths incubated with anti-ScSn (Table 2).

Glutamine (10 mM) was able to override the effect of $0.1 \mu \mathrm{g}$ DON: antigen expression was not detectable on CBA or ScSn 'ao' outgrowths. It was not possible, however, to override the inhibition caused by 1 or $20 \mu \mathrm{g} \mathrm{DON} / \mathrm{ml}$ with $10 \mathrm{mM}$-glutamine, and $20 \mathrm{mM}$-glutamine caused cell death.

Glucosamine (10 mM) caused cell death and $5 \mathrm{mM}$-glucosamine was unable to override the effect of DON. 


\section{PLATE 1}
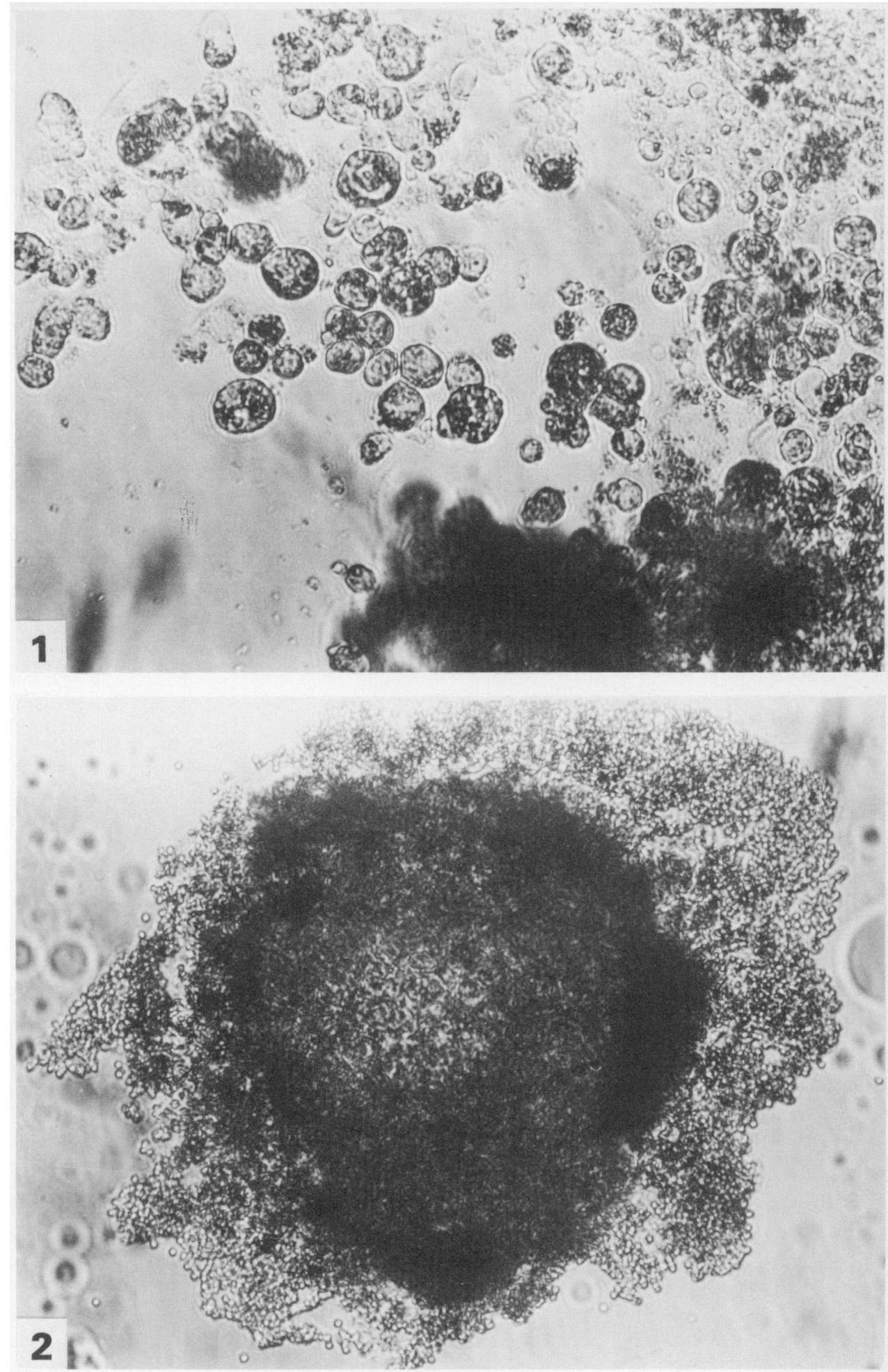

Fig. 1. A 4-day culture of 8-day mouse ectoplacental cone cells in $0 \cdot 1 \mu \mathrm{g} \mathrm{DON} / \mathrm{ml} . \times 125$.

Fig. 2. A 24-h culture of 8-day mouse ectoplacental cone cells in $0.1 \mu \mathrm{g}$ DON $/ \mathrm{ml}$. Sensitized red blood cells used in the mixed haemadsorption assay are attached to all the cells of the outgrowth. $\times 125$. 
Table 2. The effect of DON with or without glutamine or glucosamine on antigenic expression of ectoplacental cone outgrowths from CBA $\times \mathrm{CBA}$ and $\mathrm{ScSn} \times \mathrm{ScSn}$ matings

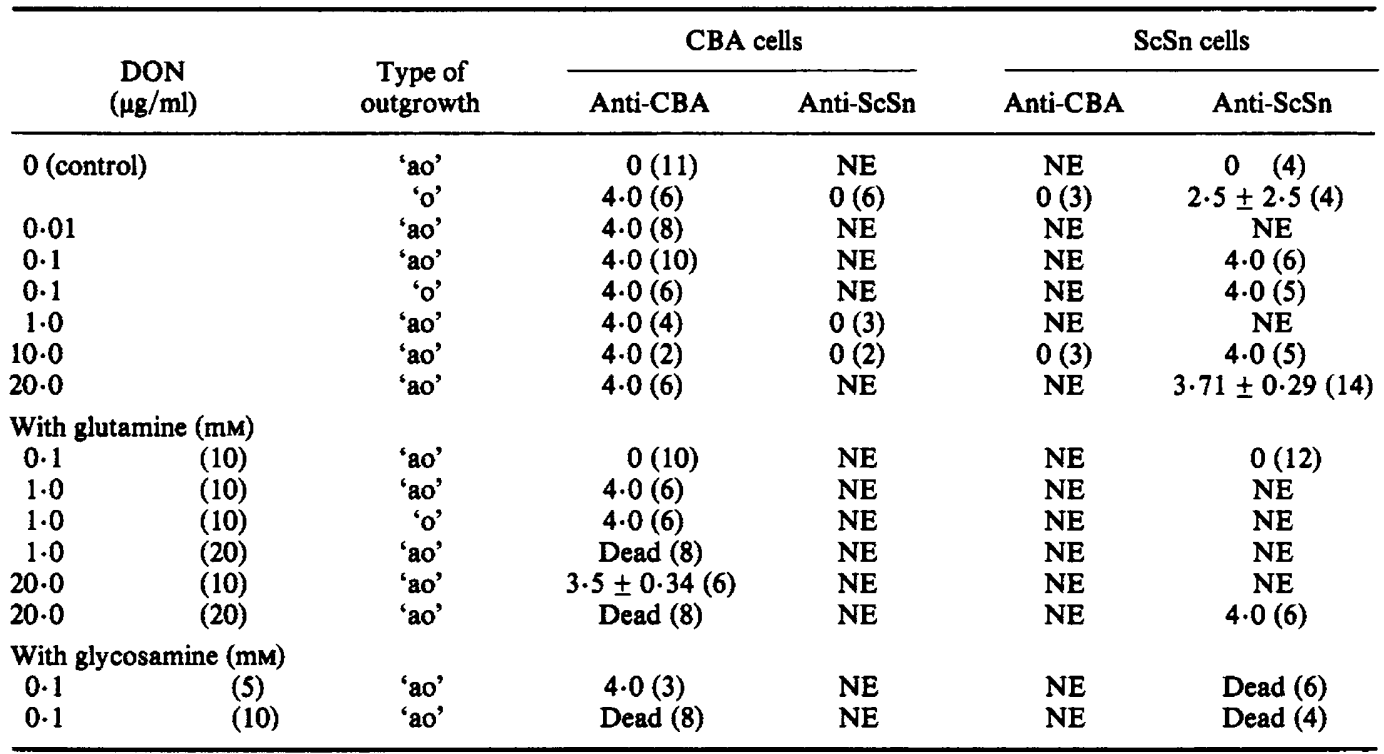

Results are expressed as mean score (see text) \pm s.e.m. The no. of outgrowths examined is given in parentheses.

$\mathrm{NE}=$ not examined.

\section{Effect of DON on surface immunoglobulin and Thy-1.2 antigen of CBA lymphocytes}

The surface fluorescence labelling of lymphocytes and thymocytes for immunoglobulin and Thy-1.2 antigen was not affected by incubation with DON for $24 \mathrm{~h}$ (Table 3).

Table 3. Surface labelling of lymphocytes, cultured with or without DON, expressed as the percentage of fluorescing lymphocytes per 200 cells counted

\begin{tabular}{lccc}
\hline & $\begin{array}{c}\text { DON } \\
(\mu \mathrm{g} / \mathrm{ml})\end{array}$ & Thy-1.2 & Ig \\
\hline Thymus cells & 0 (control) & 34.96 & - \\
& 10 & 41.08 & - \\
& 20 & 40.38 & - \\
Lymph node cells & 0 (control) & 29.80 & 7.84 \\
& 10 & 22.94 & 11.30 \\
& 20 & 29.41 & 7.69 \\
\hline
\end{tabular}

\section{Discussion}

The secondary giant trophoblast cells of the 8-day mouse ectoplacental cone do not express the histocompatibility antigens that occur on primary giant trophoblast cells (Carter, 1978). The present study has demonstrated that antigens are present on the secondary giant cells but are masked by glycosaminoglycans or glycoproteins, the synthesis of which is inhibited by 6-diazo-oxo-5-L-norleucine (DON). After incubation with DON for $24 \mathrm{~h}$ histocompatibility antigens can be detected on the secondary giant cells from $\mathrm{CBA} \times \mathrm{CBA}$ and $\mathrm{ScSn} \times \mathrm{ScSn}$ matings. 
Morulae incubated with DON were able to cavitate but were unable to hatch. Early blastocysts were also unable to hatch although the blastocoele cavity increased in size. The late biastocyst was able to hatch but did not attach and outgrow. Therefore DON could not inhibit an already determined event but could prevent further development. These data are in agreement with those of Glass, Spindle \& Pederson (1979), although they were able to maintain cultures in much higher concentrations of DON.

The early development of secondary giant cells in vitro was not affected by low concentrations of DON, there was no difference in outgrowth size of numbers of "broken-out" cells (Carter, 1978). After 3-4 days in culture a few cells had lost the ability to adhere to the rest of the outgrowth and were in suspension. This would indicate that the glycoprotein needed for adhesion of secondary giant cells is not greatly affected by low concentrations of DON. At high concentrations all cells of the outgrowth were in suspension after 4-5 days.

DON had no effect on the antigenic expression of primary giant cells of CBA mice; maximum scores were obtained before and after treatment. The primary giant cells of ScSn mice, however, did show an increase in attachment of sensitized sheep RBCs in the mixed haemadsorption assay after incubation with DON. This would suggest differences in the amount of masking agent produced by the primary giant cells in the two strains. Similar results were obtained with secondary giant cells. The response of ScSn 'o' outgrowths was 2.5 before DON treatment whilst a score of 4.0 was always obtained with CBA 'o' outgrowths. Both CBA and $\mathrm{ScSn}$ 'ao' and 'o' outgrowths were totally covered with sheep RBCs after incubation with DON. These results show that primary giant cells of $\mathrm{ScSn}$ mice can synthesize a masking substance which is not present on the equivalent cells of CBA mice and that, unlike those of CBA mice, not all the cells of the $\mathrm{ScSn}$ secondary giant cell 'o' outgrowths lose their ability to produce the masking substance during culture.

Although DON is able to inhibit the synthesis of a cell surface component over the total surface of 'ao' and the centre of ' $O$ ' secondary giant cell outgrowths of CBA mice, this does not indicate whether the outer layers of cells of the 'o' cultures which express antigen after 4 days in culture (Billington et al., 1977; Carter, 1978) lose the ability to synthesize the masking substance or simply migrate away from the source of production. Data from the ScSn 'o' cultures suggests that the former is probable.

It is possible that DON may have other more general effects on glycoprotein synthesis, including inhibition of the antigenic determinants detected in the mixed haemadsorption assay. However, SDS-polyacrylamide gel electrophoresis has shown that protein profiles of $24 \mathrm{~h}$ cultures of ectoplacental cone cells with or without DON are indistinguishable (K. M. Devine \& J. Carter, unpublished observations). The fact that cell surface markers on lymphocytes are unaffected by culture in DON is also consistent with the suggestion that DON is not inhibiting total glycoprotein synthesis. Furthermore, H-2 antigens have been shown to retain their antigenicity even after enzymic removal of sugar groups (Shreffler \& David, 1975) and glycosylation is not a prerequisite for correct insertion and cleavage of membrane proteins (Garoff \& Schwarz, 1978; Rothman, Katz \& Lodish, 1978). Secondly, it is possible that the masking substance has a rapid turnover and needs to be constantly synthesized whilst the antigen is not as frequently renewed. Although the precise identity of the antigens detected here is not known, preliminary experiments using recombinant strains have shown them to be linked to the $\mathrm{H}-2 \mathrm{~K}$ region (J. Carter \& C. Hetherington, unpublished observations) and it is possible that, as in the case of $\mathrm{H}-2$ glycopeptides, antigenicity may be retained although the carbohydrate part of the glycoprotein has been inhibited by DON.

DON competes with glutamine for the aminotransferase that converts fructose 6-phosphate to glucosamine 6-phosphate (Ghosh et al., 1960; Ellis \& Sommar, 1972; Trujillo \& Gan, 1973) and lack of hexosamines prevents the elongation of carbohydrate components of glycosaminoglycans and glycoproteins (Greene \& Pratt, 1977). Concurrent incubation with glutamine or glucosamine would be expected to overcome the inhibitory effect of DON on the synthesis of 
the surface-masking substance. Glutamine did reverse the effect but glucosamine did not, possibly because it is toxic at the levels necessary to prevent DON inhibition. Others have also reported that glucosamine can be toxic (Kim \& Conrad, 1974; Ekblom et al., 1979; Hurmerinta et al., 1979). This reversal by glutamine makes it unlikely that DON is having its effect on antigen expression via some action outside transaminidation.

DON can interrupt pregnancy at mid-term and at the time of implantation (Thiersch, 1957; Jackson, Robson \& Wander, 1959) in mice and rats. In mice injected on the 1st and 6th day of gestation, no placental remains were detected although a few intact placentae were found following the death of the fetuses when the drug was injected on Day 11. Although Thiersch (1957) and Jackson et al. (1959) suggest that DON was acting by directly depressing the growth of the developing fetus, it is also possible that there could have been effects on a masking component of the trophoblast cells.

The trophoblast is likely to play a crucial role in protecting the fetus from maternal immunological attack. Although different mechanisms may predominate during the various stages of gestation or in different species, the present study shows that antigens on the surface of mouse ectoplacental cone trophoblast are masked by a cell surface component, the synthesis of which can be inhibited by DON.

I thank Dr R. Sutcliffe and Dr J. Carroll for their helpful criticism and advice. This work was supported by the Ford Foundation.

\section{References}

Ansell, J.D. \& Snow, M.H. (1975) The development of trophoblast in vitro from blastocysts containing varying amounts of inner cell mass. J. Embryol. exp. Morph. 33, 177-185.

Billington, W.D., Jenkinson, E.J., Searle, R.F. \& Sellens, M.H. (1977) Alloantigen expression during early embryogenesis and placental ontogeny in the mouse: immunoperoxidase and mixed hemadsorption studies. Transplant. Proc. 9, 1371-1377.

Bradbury, S., Blilington, W.D. \& Kirby, D.R.S. (1965) A histochemical and electron microscopical study of the fibrinoid of the mouse placenta. J. Microsc. 84 , 199-211.

Buchanan, J.M. (1973) The amidotransferases. $A d v$. Enzymol. 39, 91-183.

Bulmer, D. \& Dickinson, A.D. (1961) The fibrinoid capsule of the rat placenta and the disappearance of the decidua. J. Anat. 95, 300-310.

Carter, J. (1976) Expression of maternal and paternal antigens on trophoblast. Nature, Lond. 262, 292293.

Carter, J. (1978) The expression of surface antigens on three trophoblastic tissues in the mouse. J. Reprod. Fert. 54, 433-439.

Chatterjee-Hasrouni, S. \& Lala, P.K. (1979) Localization of $\mathrm{H}-2$ antigens on mouse trophoblast cells. $J$. exp. Med. 149, 1238-1253.

Currie, G.A. \& Bagshawe, K.D. (1967) Masking of antigens on trophoblast and cancer cells. Lancet $\mathbf{i}$, 708.

Currie, G.A., van Doorninck, W. \& Bagshawe, K.D. (1968) Effect of neuraminidase on the immunogenicity of early mouse trophoblast. Nature, Lond. 219, 191-192.
Ekblom, P., Lash, J.W., Lehtonen, E., Nordling, s. \& Saxén, L. (1979) Inhibition of morphogenetic cell interactions by 6-diazo-5-oxo-norleucine (DON). Expl Cell Res. 121, 121-126.

Ellis, D.B. \& Sommar, K.M. (1972) Biosynthesis of respiratory tract mucins. II. Control of hexosamine metabolism by L-glutamine: D-fructose 6-phosphate aminotransferase. Biochim. Biophys. Acta 276, 105112.

Fagraeus, A., Espmark, J.O. \& Jonsson, J. (1965) Mixed haemadsorption. A mixed antiglobulin reaction applied to antigens on a glass surface. Immunology 9, 161-175.

Gardner, R. (1975) Origins and properties of trophoblast. In Immunobiology of Trophoblast, pp. 43-61. Eds R. G. Edwards, C. W. S. Howe \& M. H. Johnson. Cambridge University Press.

Garoff, H. \& Schwarz, R.T. (1978) Glycosylation is not necessary for membrane insertion and cleavage of semiliki forest virus membrane proteins. Nature, Lond. 274, 487-490.

Ghosh, S., Blumenthal, H.J., Davidson, E.A. \& Roseman, S. (1960) Glucosamine metabolism. V. Enzymatic synthesis of glucosamine-6-phosphate. $J$. Biol. Chem. 235, 1265-1272.

Glass, R.H., Spindle, A.I. \& Pederson, R.A. (1979) Mouse embryo attachment to substratum and interaction of trophoblast with cultured cells. J. exp. Zool. 208, 327-336.

Greene, R.M. \& Kochlar, D.M. (1975) Limb development in mouse embryos: protection against teratogenic effects of 6-diazo-5-oxo-L-norleucine (DON) in vivo and in vitro. J. Embryol. exp. Morph. 33, 355-370.

Downloaded from Bioscientifica.com at 04/26/2023 10:11:30AM 
Greene, R.M. \& Pratt, R.M. (1977) Inhibition by diazo-oxo-norleucine (DON) of rat palatal glycoprotein synthesis and epithelial cell adhesion in vitro. Expl Cell Res. 105, 27-37.

Grösser, O. (1925) Uber fibrin and fibrinoid in der placenta. Z. Anat. EntwGesch. 76, 304-314.

Hernandez-Verdun, D. (1974) Morphogenesis of the syncytium in the mouse placenta. Cell Tissue Res. 148, 381-396.

Hudson, L. \& Hay, F.C. (1976) Practical Immunology. Blackwell Scientific Publications, Oxford.

Hurmerinta, K., Thesleff. I. \& Saxen, L. (1979) Inhibition of tooth germ differentiation in vitro by 6-diazo-5-oxo-norleucine (DON). J. Embryol. exp. Morph. 50, 99-109.

Jackson, D., Robson, J.M. \& Wander, A.C.E. (1959) The effect of 6-diazo-5-OXO-L-norleucine (DON) on pregnancy. J. Endocr. 18, 204-207.

Kim, J.J. \& Conrad, H.E. (1974) Effect of D-glucosamine concentration on the kinetics of mucopolysaccharide biosynthesis in cultured duck embryo vertebral cartilage. J. biol. Chem. 249, 3091-3097.

Kirby, D.R.S. \& Cowell, T.P. (1968) Trophoblast host interactions. In Epithelial-Mesenchymal Interactions in Carcinogenesis, pp. 64-77. Eds R. Fleishmajer \& R. E. Billingham. Williams \& Wilkins, Baltimore.

Kirby, D.R.S., Billington, W.D., Bradbury, S. \& Goldstein, D.J. (1964) Antigen barrier of the mouse placenta. Nature, Lond. 204, 548-549.

Lake, P., Clark, E.A., Khorshidi, M. \& Sunshine, G.H. (1979) Production and characterisation of cytotoxic Thy-1 antibody-secreting Hybrid cells lines. Eur. J. Immun. 9, 875-886.
Rothman, J.E., Katz, F.N. \& Lodish, H.F. (1978) Glycosylation of a membrane protein is restricted to the growing polypeptide chain but is not necessary for insertion as a transmembrane protein. Cell 15, 1447-1454.

Searle, R.F., Jenkinson, E.J. \& Johnson, M.H. (1975) Immunogenicity of mouse trophoblast and embryonic sac. Nature, Lond. 255, 719-720.

Sellens, M.H. (1977) Antigen expression on early mouse trophoblast. Nature, Lond. 269, 60-61.

Shreffier, D.C. \& David, C.S. (1975) The H-2 major histocompatibility complex and the 1 immune response region: genetic variation function and organization. Adv. Immunol. 20, 125-195.

Simmons, R.L., Lipschultz, M.L., Rios, A. \& Ray, P.K. (1971) Failure of neuraminidase to unmask histocompatibility antigens on trophoblast. Nature, New Biol. 231, 111-112.

Taylor, P.V., Hancock, K.W. \& Gowland, G. (1979) Effect of neuraminidase on immunogenicity of early mouse trophoblast. Transplantation 28, 256-257.

Thiersch, J.B. (1957) Effect of 6-diazo-5-OXO-norleucine (DON) on the rat litter in utero. Proc. Soc. exp. Biol. Med. 94, 33-35.

Trujillo, J.L. Gan, J.C. (1973) Glycoprotein biosynthesis. VI. Regulation of uridine diphosphate$\mathrm{N}$-acetyl-D-glucosamine metabolism in bovine thyroid gland slices. Biochim. Biophys. Acta 304, 32-41.

Whyte, A. \& Loke, Y.W. (1978) Increased sialylation of surface glycopeptides of human trophoblast compared with fetal cells from the same conceptus. $J$. exp. Med. 148, 1087-1092.

Received 18 November 1980 